\title{
Erratum to: Exploitation of motion non-stationarity at the encoder and decoder of DVC: a review
}

\author{
Xin Zhao $^{1} \cdot$ Jiwei Liu ${ }^{1} \cdot$ Guangda Hu ${ }^{1}$
}

Published online: 7 September 2016

(C) Springer Science+Business Media New York 2016

\section{Erratum to: Multimed Tools Appl \\ DOI: 10.1007/s11042-016-3720-8}

In the original publication, the Tables 1 and 2 were incorrectly presented. These tables were corrected in the original version.

The online version of the original article can be found at http://dx.doi.org/10.1007/s11042-016-3720-8

\section{Xin Zhao}

huagong03031403@163.com

1 School of Automation, University of Science and Technology Beijing, Beijing 100083, China 